\title{
O Pibid e a formação inicial de professores: contribuições à prática educativa inclusiva
}

\section{The Pibid and the teachers initial training: contributions to inclusive educational practice}

\section{El Pibid y la formación inicial de profesores: contribuciones a la práctica educativa inclusiva}

\author{
Eliane Rodrigues Martins ${ }^{1}$ \\ Geandra Cláudia Silva Santos ${ }^{1}$ \\ DOI: http://dx.doi.org/10.20435/serie-estudos.v0i0.1284
}

\begin{abstract}
Resumo: O objetivo da pesquisa consistiu em investigar as contribuições do Programa Institucional de Bolsa de Iniciação à Docência (Pibid) do curso de Pedagogia, para a formação inicial de professores, como aspecto relevante à prática educativa inclusiva. A metodologia fundamentou-se na perspectiva qualitativa, por meio de pesquisa de campo. Participaram da investigação quatro professoras egressas da Pedagogia de uma universidade pública, as quais foram integrantes como bolsistas de iniciação à docência no subprojeto de educação especial inclusiva. Para a produção das informações, optou-se pela entrevista semiestruturada, questionário e análise documental. Os resultados demonstraram que as participantes avaliaram a experiência no Pibid como positiva, tornando a formação e a atuação profissional mais significativa por meio da articulação teoria e prática, que permitiu planejar e realizar atividades capazes de inserir, em certa medida, os alunos no currículo e ampliar as relações interpessoais, apesar da estrutura e organização excludente da escola. Conclui-se que as possibilidades construídas no Pibid ensejam aos futuros professores subsídios orientadores da problematização da realidade escolar e formulação de alternativas pedagógicas.
\end{abstract}

Palavras-chave: formação inicial de professores; Pibid; Pedagogia; educação especial; inclusão.

\begin{abstract}
This research aimed to investigate the contributions of the Institutional Program of Initiation to Teaching Grant (Pibid) of the Pedagogy course, for the initial formation of teachers, as a relevant aspect to the inclusive educational practice. The methodology was based on the qualitative perspective, through field research. Four female teachers from Pedagogy, from a Public University, participated in the research. They were members of the subproject for the special inclusive education grant. For the production of the information, the semi-structured interview, questionnaire, and documentary analysis were adopted. The results showed that the participants have evaluated the experience in Pibid as positive, making formation and professional performance more meaningful through the articulation of theory and practice, which allowed to plan and carry
\end{abstract}

1 Universidade Estadual do Ceará (Uece), Tauá, Ceará, Brasil. 
out activities capable of inserting, to a certain extent, the students in the curriculum and rise interpersonal relationships, despite the exclusionary structure and organization of the school. It was concluded that the possibilities built of the Pibid provide the future teachers with the production of guiding subsidies to the problematization of the school reality and the formulation of pedagogical alternatives.

Keywords: teacher initial training; Pibid; Pedagogy; special education; inclusion.

Resumen: El objetivo de esta pesquisa fue investigar las contribuciones del Programa Institucional de Beca de Iniciación a la Docencia (Pibid) del curso de Pedagogía, para la formación inicial de docentes, como un aspecto relevante para la práctica educativa inclusiva. La metodología se basó en la perspectiva cualitativa, a través de la investigación de campo. Cuatro maestras de Pedagogía de una Universidad Pública participaron de la investigación. Eran miembros, como becarias de iniciación a la docencia, del subproyecto de educación especial inclusiva. Para la producción de la información, se adoptaron la entrevista semiestructurada, el cuestionario y el análisis documental. Los resultados mostraron que los participantes han evaluado la experiencia en Pibid como positiva, haciendo que la formación y el desempeño profesional sean más significativos a través de la articulación de la teoría y la práctica, lo que permitió planificar y realizar actividades capaces de insertar, hasta cierto punto, a los estudiantes en el currículo y el aumento de las relaciones interpersonales, a pesar de la estructura de exclusión y organización de la escuela. Se concluyó que las posibilidades creadas en el Pibid brindan a los futuros docentes la producción de subsidios orientadores para la problematización de la realidad escolar y la formulación de alternativas pedagógicas.

Palabras clave: formación inicial de docentes; Pibid; Pedagogía; educación especial; inclusión.

\section{INTRODUÇÃO}

Na elaboração e implantação de políticas públicas, a sociedade anseia pela ascensão de projetos que expressem os princípios de democratização e igualdade em todas as áreas. A educação é um dos direitos centrais que devem chegar a todos e permitir o acesso a oportunidades de escolarização ampla e igualitária, conforme defende o paradigma da educação inclusiva assumida pelos marcos regulatórios brasileiros, com implicações substanciais na formação dos profissionais.

Historicamente, a formação inicial de professores está situada no panorama das políticas públicas e nos seus processos de operacionalização (FERNANDES; CUNHA, 2013). Os estudos sobre formação inicial de professores articulados à educação especial vêm se configurando como um cenário de exigências para mudanças no processo de formação e atuação dos profissionais na escola. A perspectiva inclusiva vigente nas políticas educacionais brasileiras relacionadas especificamente aos alunos público-alvo da educação especial (PAEE) ${ }^{2}$ evidencia

2 Alunos com deficiência, transtorno global do desenvolvimento e altas habilidades/superdotação. 
que as escolas devem desenvolver práticas pedagógicas capazes de ensejarem a participação efetiva no processo de ensino na escola comum, com suporte do Atendimento Educacional Especializado (AEE). (BRASIL, 2008, 2013).

Contudo, essas conquistas legais e políticas ainda estão em descompasso com a realidade escolar. Portanto, é um desafio a construção de uma escola inclusiva, justamente por tramitar em uma sociedade excludente e desigual. Os descompassos são reforçados pela escassez ou precariedade de ações políticas em favor da formação dos professores para desenvolver seu ofício profissional em um contexto escolar cada vez mais complexo, em virtude da democratização do acesso à educação pública e, contraditoriamente, da crescente desvalorização do magistério na conjuntura atual. Diniz-Pereira (2011) entende que, nessa conjuntura, emerge uma preocupação no que se refere ao desinteresse das novas gerações pela carreira docente, que se explica, entre outros motivos, pela baixa expectativa de renda em relação à futura profissão e pelo declínio do status social da docência.

É nesse contexto que o Pibid se constitui como uma política de governo direcionada à formação inicial complementar, visando à concretização de ações de valorização do magistério e incentivo à formação, por meio da promoção da relação entre Universidade e escola. Gonzatti (2015, p. 19) afirma:

[...] o Pibid fomenta um movimento de ruptura e renovação das concepções epistemológicas e filosóficas sobre ensino, aprendizagem e formação que estão subjacentes à maioria dos currículos e práticas dos cursos de formação no Brasil, incentivando o desenvolvimento de inovações educativas.

No escopo do Pibid, o presente artigo selecionou o subprojeto de um dos cursos de Pedagogia da Universidade Estadual do Ceará (Uece), voltado à educação especial. Inclusive, é o único subprojeto da Uece interessado nessa temática e um dos poucos existentes, em nível nacional. Com isso, o objetivo geral da pesquisa consistiu em investigar as principais contribuições do Pibid de Pedagogia para a formação inicial de professores, como aspecto relevante para a prática docente inclusiva.

Na sequência, apresentamos breve discussão teórica a respeito da formação docente na perspectiva inclusiva, para respaldar a análise das informações produzidas na pesquisa realizada. 


\section{FORMAÇÃO DE PROFESSORES E ESCOLA INCLUSIVA}

As transformações na sociedade acarretam mudanças no campo educacional, com implicações importantes na formação profissional, resultando em marcas de avanços e retrocessos ante o contexto político-social em curso. Pensar a relação entre formação docente e inclusão escolar revela que precisamos avançar nas discussões voltadas a "todo o sistema educacional, desde o processo de formação até a estrutura e organização da escola" (OLIVEIRA, 2010, p. 145). Torna-se incipiente discutir e propor melhorias no processo formativo, é preciso melhorar todas as dimensões educacionais para que os professores, ao ingressarem no sistema regular de ensino, desenvolvam uma prática pedagógica condizente com a realidade dos alunos, bem como tenham suporte, estrutura e materiais acessíveis para que todos desenvolvam seus conhecimentos.

A educação dos alunos PAEE demanda que os professores, na formação inicial, estudem conhecimentos sobre a educação inclusiva, visto que muitos professores da educação básica apresentam dúvidas, incertezas e não se sentem preparados para trabalhar com a diversidade de alunos matriculados nas escolas (SOUSA, 2016). Para Oliveira (2010, p. 144): “[...] não há dúvidas, na atualidade, da absoluta necessidade de uma formação inicial, para todos os professores, sejam pedagogos ou licenciados, que aborde a temática da diversidade, da diferença e das necessidades educacionais especiais [...]".

Nesse processo, chamamos atenção para a importância dos investimentos em políticas públicas de formação inicial e continuada de professores, pelo fato de oferecerem condições e possibilidades que levem os docentes a organizar o trabalho pedagógico em função do ensino e da aprendizagem dos alunos PAEE. Aliados a esses processos, que sejam contemplados simultaneamente com a valorização do magistério por meio das condições objetivas necessárias, como salário, carreira, formação, entre outros aspectos (MOURA; VIANA, 2015).

Em relação à formação de professores para atuar na educação especial, a Política Nacional de Educação Especial na Perspectiva da Educação Inclusiva (Pneepei) determina que "para atuar na educação especial, o professor deve ter como base da sua formação, inicial e continuada, conhecimentos gerais para o exercício da docência e conhecimentos específicos da área" (BRASIL, 2008, p. 13). A Pneepei mostra especificações somente quando se trata do professor do AEE, que deve dominar uma multiplicidade de conhecimentos e 
habilidades para cumprir o papel do serviço de complementar e suplementar a educação geral.

Caso o professor não atue no AEE, deverá estar habilitado para trabalhar com os alunos na sala comum e ter o seu processo de formação continuada garantido pelos sistemas de ensino que assegurem articular o comum e o específico (BRASIL, 2008). Para Oliveira (2010, p. 144):

O desafio é justamente proporcionar uma formação que não se distancie da formação geral e, ao mesmo tempo, desenvolva a competência profissional para o trabalho pedagógico frente aos alunos com necessidades educacionais especiais.

Para que realmente haja a participação dos alunos PAEE no ensino comum, a organização pedagógica da escola deve ensejar, com a colaboração de todos os segmentos, a imprescindível articulação entre professores da sala comum e do AEE, apoiada pela família dos alunos. Souza, Costa e Holanda (2015) ratificam a problemática, ao assinalar que a interlocução entre professores do AEE e do ensino comum é fundamental para superar a desarticulação e o individualismo presente na prática escolar. Romper a lógica fragmentada do trabalho pedagógico na escola constitui-se um dos maiores desafios para aproximação da realização de práticas educativas, apesar dos projetos pedagógicos das instituições de ensino defenderem o contrário.

A formação dos professores comuns e especializados, igualmente dos outros profissionais da escola, torna-se muito desafiante e deve ser constituída com a devida complexidade com que a tarefa é requerida na escola, sob pena de reforçar a exclusão, mesmo quando os alunos venceram, em certa medida, as barreiras de acesso à escola.

\section{METODOLOGIA DA PESQUISA}

O estudo configura-se como uma pesquisa de natureza qualitativa, pois evidencia a importância em que os participantes da pesquisa podem formular opiniões e reflexões sobre a realidade na qual estão inseridos no campo educacional. Apoiando-se nessa abordagem, desenvolvemos uma pesquisa de campo, pois essa acolhe as informações diretamente da população investigada e permite uma aproximação com a realidade dos participantes, na tentativa de compreender como o fenômeno se expressa. 
Participaram da pesquisa quatro professoras egressas do curso de Pedagogia, que atuaram como bolsistas de iniciação à docência (BID) no subprojeto "Aprendiz da docência no contexto da educação inclusiva", num campus da Universidade Estadual do Ceará (Uece), no sertão cearense, no período 2014-2018.

A opção pela participação dessas alunas se justificou pelo fato de elas, além de egressas do referido curso de graduação e Pibid, terem atuado no período de realização da investigação como professores da Educação Básica, ensinarem ou terem sido professoras de alunos PAEE. As participantes serão nomeadas como E1, E2, E3 e E4, garantindo o direito de confidencialidade das suas identidades, conforme os princípios éticos indicados no termo de consentimento livre e esclarecido assinado por elas para a realização da pesquisa.

As participantes são do sexo feminino, com idades entre 24 e 26 anos, e lecionavam em escolas de Educação Básica. A forma de ingresso na atividade profissional: E1 ingressou por meio de concurso público, tornando-se funcionária efetiva; E2, E3 e E4 ingressaram por meio de seleção pública, em regime de trabalho temporário. A participante E1 atuava há 3 anos no Ensino Fundamental, anos iniciais, e não cursou pós-graduação; E2 estava como professora da sala de recursos multifuncionais, atuava há 1 ano e 9 meses no magistério e cursava pós-graduação lato sensu em Educação Especial; E3 atuava como professora da Educação Infantil há 10 meses e, até o momento da pesquisa, não havia cursado pós-graduação; E4 estava como professora no Ensino Fundamental, anos iniciais, atuava há 3 anos no magistério e tinha pós-graduação lato sensu em Educação Especial e Inclusiva.

As técnicas de coleta de dados utilizadas, inicialmente, foram a entrevista semiestruturada, aplicada com as participantes E1 e E2, e o questionário, aplicado com as participantes E3 e E4. Ambos tiveram a finalidade de obter informações relacionadas às experiências vivenciadas no Pibid e suas contribuições para a prática profissional junto aos alunos com NEE. Por último, foi realizada a análise dos seguintes documentos: Portaria n. 096/2013, que regulamentava o Pibid, no período 2014-2018; Proposta Institucional do Pibid na Uece; Proposta do subprojeto de Pedagogia. O estudo desses documentos possibilitou conhecer objetivos, estrutura, organização, funções dos bolsistas e atividades do Pibid, nos âmbitos nacional e local. 


\section{O PIBID COMO CAMPO DE ESTUDO}

O Pibid foi lançado em 2007, pelo Ministério da Educação (MEC) e pela Coordenação de Aperfeiçoamento de Pessoal de Nível Superior (Capes). A Portaria n. 096/2013 instituiu que o Programa objetivou "[...] fomentar a iniciação à docência, contribuindo para o aperfeiçoamento da formação de docentes em nível superior e para a melhoria da qualidade da educação básica pública brasileira", bem como a valorização do magistério (BRASIL, 2013, p. 2).

Os objetivos estabelecidos na Portaria 96/2013, entre outros, são: elevar a qualidade da formação inicial, por meio da integração ensino superior e educação básica; articular teoria e prática; proporcionar a inserção no cotidiano escolar em busca de superação dos problemas pertinentes ao ensino e à aprendizagem; e converter os professores da educação básica na escola em coformadores dos futuros professores (BRASIL, 2013).

Os objetivos sinalizam para a ressignificação do espaço escolar como ambiente de formação, apropriação de conhecimento, construção dos saberes e da identidade docente. Assis (2016) afirma que a escola é tomada como lócus de formação, tornando possível a ação-reflexão sobre o fazer docente desde o início do curso de graduação.

O incentivo à docência, por parte do Pibid, deve ser capaz de atrair os licenciandos para ingressarem na carreira docente desde o início do curso de graduação, possibilitando a inclusão dos estudantes no contexto das escolas públicas brasileiras. Na visão de Fernandes e Cunha (2013, p. 55), a inserção do professor no campo profissional na formação inicial auxilia o fortalecimento da identidade dos cursos de licenciaturas e ao mesmo tempo sinaliza a possibilidade de uma prática "que traga a reflexão como um processo dialético e contextualizado nas condições objetivas do mundo da vida e do trabalho".

Para tanto, o Pibid abrange não somente os estudantes das Instituições de Educação Superior (IES) que cursam as licenciaturas, como também envolve professores em efetivo exercício da docência nas escolas, compreendendo-os como coformadores na função de bolsista supervisor do BID no contexto escolar, e professores dos cursos de licenciatura que se convertem em coordenadores de área e coordenador institucional, no âmbito da IES.

Para integrar o Pibid, a Uece desenvolveu o projeto A Vida Docente na Escola: aprender e ensinar pela pesquisa - FASE II, no período de 2014-2018, e 
contou com 29 subprojetos, abrangendo, em sua escala, 1.071 bolsas de iniciação à docência, distribuídas entre os campi da capital e do interior. O projeto teve como objetivo "a aprendizagem da docência centrada na escola como lugar de formação e de pesquisa e está delineada com fundamento nos parâmetros da reflexividade e da epistemologia da prática" (UECE, 2013, p. 2).

Inscrito no projeto da UECE, o subprojeto do curso de Pedagogia objetivou:

[...] promover a inserção dos alunos do curso de Pedagogia do CECITEC no cotidiano escolar, para conhecer, compreender o processo educativo no qual estão incluídos os alunos com NEE e construir alternativas pedagógicas, ao partilharem saberes e práticas com os professores. (CECITEC, 2013, p. 2).

O subprojeto em estudo, do curso de Pedagogia, pretendeu motivar os bolsistas a

[...] ressignificarem a realidade escolar como espaço de formação, em que a possibilidade concreta de estabelecer o diálogo entre teoria e prática resulte na construção dos saberes necessários ao enfrentamento dos desafios da profissão docente. Esse projeto pode contribuir com a ampliação do direito à educação dos alunos com NEE, investindo em ações pedagógicas voltadas à aprendizagem e não somente à socialização; assim como poderá colaborar com a formação continuada dos professores das instituições de ensino. (CECITEC, 2013, p. 2).

O subprojeto era formado por $40 \mathrm{BID}$, dois coordenadores de áreas e oito supervisores, desenvolvendo suas atividades em seis escolas públicas municipais e sendo realizado em instituições de Educação Infantil e Ensino Fundamental que tinham, em suas dependências, sala de recursos multifuncionais.

As atividades desenvolvidas pelos bolsistas na escola consistiam no acompanhamento pedagógico individualizado dos alunos PAEE na sala de aula comum, dando suporte ao professor no desenvolvimento da sua ação didática, bem como no auxílio ao trabalho do professor do AEE, apoiando na efetivação das atividades direcionadas aos alunos PAEE, de forma a possibilitar a ampliação desse atendimento. Ademais, os bolsistas promoviam ações coletivas na escola, para sensibilizar e socializar informações/conhecimentos que ensejassem posturas mais condizentes com a perspectiva inclusiva (CECITEC, 2013).

A seguir, apresentamos a análise e discussão das informações produzidas na pesquisa, organizadas a partir de questões-chave que nortearam a investigação e 
tornaram possível compreender as contribuições do Pibid para a formação inicial de professores, como aspecto relevante à prática docente inclusiva.

\section{PIBID E FORMAÇÃO INICIAL DE PROFESSORES: CONTRIBUIÇÕES À PRÁTICA EDUCATIVA INCLUSIVA}

As participantes foram questionadas sobre as razões para o ingresso no Pibid:

A temática do projeto, por ser da educação inclusiva, e a questão também de ser a área da pesquisa [...]. (E1).

[...] eu primeiro pensei no currículo, claro que a parte financeira pra quem é estudante que vem do interior também contribuiu muito, mas eu me interessei pelo currículo, porque vi que era um programa rico, a oportunidade de refletir e de vivenciar experiências e dessas experiências tirar resultados. (E2). [...] foi a experiência, saber que o mesmo iria me possibilitar vastos conhecimentos e que iriam contribuir bastante para a minha formação tanto acadêmica como profissional. (E3).

Além do incentivo financeiro, a prática e o currículo foram meus maiores motivadores. (E4).

As falas das participantes apontam para a compreensão do Pibid como formação complementar à sua graduação (SANTOS, 2018; FARIAS et al., 2014), ao propiciar o enriquecimento curricular da formação na licenciatura, indicando a experiência/prática como aspecto relevante (E2, E3, E4). E1 destaca explicitamente a oportunidade de discutir e pesquisar sobre a área da educação especial. As respostas de E2 e E4 também chamam atenção para o incentivo financeiro, por meio da bolsa recebida mensalmente, como mecanismo de custear a formação e dar prosseguimento aos estudos, pois a maioria dos BID eram oriundos de camadas sociais desfavorecidas.

Ao serem provocadas a descreverem as atividades do Pibid realizadas na Universidade e na escola, as participantes responderam:

Enquanto bolsista a gente tinha as formações, se apropriava da teoria do que os teóricos falavam sobre o contexto histórico da educação especial e sobre os tipos de deficiência e tinha também o trabalho nas escolas, que, no meu caso, acompanhei uma aluna com deficiência visual [...]. Tivemos o trabalho de conhecer o entorno do aluno, não só dentro da escola, mas também familiar. [...] acompanhei a aluna tanto dentro da sala de aula e dentro da sala de recurso multifuncional e aí depois a gente foi fazendo 
projetos, atividades que fossem favorecer a aprendizagem dessa aluna e que não era como reforço. (E1).

[...] depois da época de leitura, pesquisa e reflexão a gente passou para a prática como um todo. Os momentos na sala regular fazíamos um trabaIho com o aluno com deficiência. Na sala do AEE a gente acompanhava as professoras no planejamento, acompanhava no atendimento e na ação. Então era uma prática bem global, não somente voltada aos alunos com deficiência, era voltada a toda a escola, para toda estrutura compreender a inclusão. (E2).

Na condição de bolsista na escola acompanhava uma criança autista, criando estratégias para favorecer o processo de ensino e aprendizagem das crianças, além de analisar documentos da escola, oficinas para a comunidade escolar e momentos de formação com funcionários da instituição para conscientizá-los da importância da inclusão das crianças com NEE no ambiente escolar. Já na universidade tínhamos os momentos de formação, oficinas. (E3).

Estudos de diversos textos, encontros formativos, acompanhamento do aluno com necessidades educacionais especiais, planejamento, debates [...]. (E4).

Tomando como referência os relatos das participantes, as atividades realizadas no Programa envolviam uma diversidade de espaços, situações, ações e agentes escolares, inclusive fora das instituições de ensino, ao visitarem as residências dos alunos e produzirem informações sobre o âmbito familiar, visando à avaliação das NEE dos alunos acompanhados pelos BID. As ações indicadas pelas participantes se inscrevem no conjunto de atividades previstas no subprojeto do curso de Pedagogia. Vejamos: estudos de textos teóricos, análise dos documentos da escola e do AEE, estudo de caso dos alunos com NEE, incluindo a avaliação das necessidades educacionais nos âmbitos do aluno, escola e família; investigação da prática pedagógica na sala comum e no AEE, oficinas de elaboração de atividades e construção de recursos didáticos adaptados, planejamento e intervenção colaborativa nos espaços da sala comum e no AEE, entre outras (CECITEC, 2013).

A multiplicidade de aspectos considerados na realização do subprojeto demonstra a tentativa de situar a educação especial no âmbito da organização pedagógica da escola, afirmando-a como incumbência de todos os agentes educativos, afinal, o aluno, ao ser matriculado, torna-se responsabilidade da Instituição e do sistema de ensino. A Pneepei (BRASIL, 2008) marca incisivamente a integração do AEE no projeto político-pedagógico da escola e a articulação entre os professores 
da educação especial e do ensino comum. Para Souza, Costa e Holanda (2015, p. 225), a "interlocução dos saberes destes profissionais, respeitados os limites de suas especificidades, é sempre salutar, devendo convergir para um mesmo objetivo que é o desenvolvimento do aluno".

Na sequência, questionamos em quais aspectos a participação no Pibid impactou o desempenho acadêmico no curso:

Afetou positivamente meu desempenho acadêmico [...], o que eu estava adquirindo era mais conhecimento que poderia me ajudar nas outras disciplinas e na minha prática. (E1).

Afetou positivamente na questão do debate, da discussão em outras disciplinas, como também na área da escrita e, na hora de produzir trabalhos, as ideias surgiam com mais facilidade [...]. (E2).

Posso dizer que afetou de forma muito significativa em todos os aspectos, o Pibid contribuiu mais para a minha formação, até mais do que a Universidade, pois tive a oportunidade de ter contato com a prática e ver a realidade das escolas. Outro aspecto que contribuiu para o desenvolvimento profissional, o Pibid, que contribuiu bastante a forma de me expressar e lidar com o público e o dinamismo em sala de aula. (E3).

Sim, permitiu falar com confiança, adquiri conhecimentos que me acompanham até hoje, podendo assim aprimorar minha prática no dia a dia da sala de aula. (E4).

Para as egressas, de modo geral, o Pibid impactou de forma positiva seus desempenhos acadêmicos, pois possibilitou alcançar patamares satisfatórios de conhecimento, desenvolvimento de habilidades e posturas pertinentes à profissão docente, desenvoltura na comunicação em público, investimentos na aprendizagem da leitura e escrita acadêmica. Esses são aspectos exigidos nos objetivos gerais do Pibid (BRASIL, 2013) e do Projeto Institucional da Universidade (UECE, 2013), revelando a coerência do subprojeto com as propostas orientadoras do Programa.

As contribuições da experiência formativa do Pibid ao estudo das outras disciplinas do curso, confirmando seu caráter complementar à formação inicial dos bolsistas, bem como a ênfase recorrente dada à parte prática, expõem, de certa forma, as múltiplas lacunas dos currículos de graduação traduzidas em necessidades educacionais dos licenciandos, quando acessam a complexidade da realidade escolar. Isso também pode indicar que, apesar de o subprojeto tratar de uma temática específica como a educação especial, a condução do subprojeto 
ajudou os licenciandos engajados no Pibid a atingirem uma visão ampla e integradora da Pedagogia.

As participantes analisaram a parceria entre escola e universidade na efetivação do subprojeto. Elas responderam:

O Pibid não contribuiu apenas com a escola, mas eu acredito que com as famílias com a sociedade e no geral, porque o Pibid trabalhou com os sujeitos da escola [...] que ficassem mais conscientes do que é a educação inclusiva e também com a família, de como poderia contribuir para melhorar no desenvolvimento de seu filho, e aí contribuiu também principalmente para o aluno, fazendo com que também as outras pessoas refletissem e tivessem um olhar para aquele aluno que era muitas vezes esquecido [...]. A escola contribuiu na medida em que abriu as portas para que a gente pudesse pesquisar, para que a gente pudesse conhecer a fundo e a gente conheceu mesmo o geral da escola, de documentação e de conversa com os sujeitos e na observação. (E1).

Contribuiu muito. Na sala regular, eu vi a mudança na postura do professor, em um dos primeiros momentos. Outro aspecto foi no aluno, a independência dele e a vontade própria [...]. A escola contribuiu na questão comportamental como profissional, outra coisa que contribuiu é que a escola nos ensinou a interagir com todos os funcionários da escola, de forma ampla, e a gente compreendeu que cada um faz parte daquele universo. A escola nos ensinou a prática do professor [...]. (E2).

O Pibid contribuiu bastante com a escola levando os bolsistas para que os mesmos criassem estratégias pedagógicas para ajudar no trabalho com as crianças com NEE, contribuindo para o processo de ensino e aprendizagem dos mesmos. A escola também contribuiu bastante com a nossa formação, na qual aprendemos com a realidade das escolas. (E3).

O Pibid contribuiu de forma significativa, pois os bolsistas estavam comprometidos em sempre ajudar com ideias novas, um planejamento que envolvia teoria e prática, promovendo sempre a inclusão. O ambiente escolar contribuiu de maneira que nos permitiu colocar nossos conhecimentos em prática, conhecendo assim a nossa futura realidade. (E4).

Diante dos depoimentos, a escola foi tomada como espaço de formação, possibilitando que os bolsistas fossem aprendizes da docência, colocando em análise os conhecimentos adquiridos na academia, assim como os saberes produzidos no ambiente escolar. Por outro lado, o Pibid contribuiu com a escola, à medida que conseguiu mobilizar os agentes escolares para refletirem e planejarem 
atividades em favor da inclusão, possibilitando que alguns professores envolvidos na realização do Pibid repensassem posturas diante do ensino dos alunos PAEE. Também favoreceu o processo de socialização e aprendizagem de alunos PAEE, por meio das ações compartilhadas entre BID, supervisores e outros professores da escola. Vale destacar que a complexidade inerente ao fenômeno educativo exige que as práticas sejam subsidiadas pelo estudo dos conhecimentos e demanda a assunção de uma postura crítico-reflexiva mediada pelos processos formativos.

Em seguida, as participantes avaliaram a experiência vivenciada no Pibid, de modo amplo e espontâneo:

[...] o Pibid só veio a favorecer na minha formação em todos os aspectos, eu acho que não teria uma formação tão boa se não tivesse o Pibid [...] a gente tinha os momentos de estudo que favoreceu todas as formas, as apresentações de trabalho, as trocas de experiências, as trocas de ideias, debates, os momentos mesmo de interação nos proporcionava isso, novas formas de expressar, de falar. (E1).

Eu avalio como dinâmica, foi uma experiência muito rica, a experiência que eu tive no Pibid foi acima de tudo uma experiência muito humana [...]. Então é uma experiência que eu acho que todos os alunos que fazem o curso na parte da educação deveriam ter essa experiência, seja na área de educação especial, seja na área que deseja, [...] você se torna um profissional mais confiante [...]. Nós vimos experiências de outras pessoas que eram nos repassadas e a gente construiu nossas próprias experiências no Pibid. (E2).

Foi uma experiência muito enriquecedora, na qual tive a oportunidade de ter uma outra visão da realidade das escolas [...]. (E3).

Me ajudou enquanto ser humano a ser uma pessoa melhor, disposta a ajudar o próximo, contribuiu para minha formação profissional. (E4).

Está presente nas contribuições do Pibid mencionadas pelas participantes a importância do contato com a realidade da escola para ensejar compreendê-la e trocar experiências com vários agentes educativos. Além disso, três das participantes destacaram a oportunidade de humanização proporcionada pela experiência do Pibid que deveria ser estendida aos outros universitários. Esse aspecto tributa relevância à natureza ética das relações humanas, principalmente quando se trata dos alunos PAEE, por apresentarem formas singulares de conviver e expressar suas demandas, requerendo ampliação da visão de mundo para acolher o outro marcado por diferenças que o tornam misterioso, estranho, problemático. 
A mudança no olhar lançado ao outro, neste caso, ao aluno PAEE, pode gerar uma emocionalidade estimuladora da produção de novos sentidos que resultem em alterações nas atitudes dos profissionais, com impacto nas suas ações e relações no contexto escolar. A formação pode ser um processo de produção de novos olhares, desde que supere a sua dimensão meramente técnica e inclua em sua configuração a centralidade precípua do professor como pessoa (MITJÁNS MARTÍNEZ, 2005), em um processo formativo que valorize a subjetividade dele.

O Pibid criou alternativas para desenvolver a formação inicial, de modo complementar, nos cursos de licenciatura. Apesar das análises positivas do Pibid, devemos recobrar o entendimento de que a formação dos professores tem limites, quando se trata da resolução dos problemas da categoria e do seu campo de trabalho, ao contrário da narrativa neoliberal falaciosa que responsabiliza o professor e sua formação nos contextos de crises cíclicas para justificar as reformas educacionais necessárias aos ajustes econômicos típicos da sociedade capitalista.

Moura e Viana (2015) afiançam essa reflexão ao defenderem que não se enfrentam os problemas educacionais somente com formação profissional, tampouco se resolvem problemas sociais apenas com a melhoria da educação. Ao acrescentarem, na análise, que não é possível resolver problemas na formação inicial com ações imediatistas, como programas de incentivo à formação, expõem a natureza precária e contraditória da formação inicial vigente no país, que precisa ser repensada profundamente. O Pibid como experiência formativa executada em larga escala, em diferentes realidades e por distintos cursos/áreas do conhecimento, representa um aporte imprescindível ao processo de repensar a formação de professores no Brasil.

Indagamos as participantes a respeito da importância do Pibid para a sua formação e atuação profissional, e elas revelaram que:

o Pibid reflete até hoje quando eu iniciei a minha primeira experiência na educação depois do concurso, eu fui lotada na sala de recursos multifuncional e eu gostei muito porque era algo que eu saí da universidade eu já tinha conhecimento na área, então, eu saí querendo colocar em prática tudo que eu tinha aprendido [...] (E1).

A experiência que eu tive, os momentos que eu tive no Programa eles tornaram minha atuação inovadora [...] (E2).

o Pibid na minha formação ocasionou várias mudanças, como a forma de pensar em relação à docência, bem como o meu desenvolvimento na mesma 
e a oportunidade de trazer novos conhecimentos e agregar a teoria com a prática que só se tornou possível no Pibid. Já com relação ao profissional foi através do Pibid que me senti bem mais preparada para atuar. Acredito que com as experiências vividas no Programa aprendi a planejar, a buscar novas metodologias de ensino e sobretudo estou pondo em prática na escola em que atuo. Além de melhorar a minha relação com o público (os pais dos meus alunos). (E3).

Me ajudou a conhecer o contexto escolar, pude observar práticas que segui como exemplo, enquanto outras tento nunca fazê-las. (E4).

A participação no Pibid reflete-se constantemente na prática das participantes, possibilitando, por meio da articulação entre teoria e prática promovida no percurso formativo integrado às atividades curriculares do curso de Pedagogia, um desenvolvimento favorável às atribuições profissionais requeridas na escola. Pletsch e Souza (2015) acreditam no papel decisivo da formação na atuação dos professores e considera relevante, no exercício da docência, a valorização da práxis, possivelmente como critério para garantir a sua qualidade e o impacto favorável na educação dos alunos PAEE.

As falas convergem para expressar segurança, inovação, satisfação e reflexão na organização do ato de ensinar coordenado pelas participantes. Ressaltamos a resposta de E4, ao demonstrar, em sua fala, a possibilidade de se posicionar com autoria diante das posturas pedagógicas identificadas na prática escolar, demonstrando a mediação da reflexão crítica ante a realidade. Oliveri (2017, p. 142) ressalta que "a relação de proximidade entre os docentes experientes e os professores iniciantes colabora para a constituição dos modos de ser e agir dos futuros professores", sem que isso signifique reprodução dos modelos de docência vigentes no contexto escolar.

Dessa forma, ao demarcarem os aspectos importantes aprendidos na formação inicial, por meio da participação no Pibid, questionamos diretamente a respeito da contribuição do subprojeto no trabalho junto aos alunos PAEE:

Acredito que todos os alunos que fizeram parte do subprojeto "Aprendiz da docência no contexto da educação inclusiva" foram beneficiados no intuito de que começaram a fazer com que os alunos tivessem mais acesso e oportunidade, saírem do cantinho de ficar brincando com o lápis, ou brincando com materiais e passar a ter acesso ao conhecimento [...]. (E1).

Ajudou muito na prática em relação ao planejamento, eu saberia que tinha 
que fazer um planejamento pra esses alunos [...] eu aprendi uma nova prática que é o PPI [Projeto Pedagógico Individualizado] [...] e eu estou tentando construir com os meus, como uma forma de projeto [...] vou começar pela escola, depois avaliar também o aluno e a família [...] porque o PPI é isso, na escola tem que o professor da sala regular e o professor do AEE fazerem um trabalho juntos, então eu tenho que indicar objetivos também para aquele professor alcançar, também fazer com o aluno. Na maioria das vezes ele não se sente responsável pelo aluno, ele coloca a responsabilidade na atuação do professor do AEE [...]. (E2).

Foi através do Pibid que aprendi a propor atividades e metodologias mais dinâmicas para executar para meus alunos, [...] estou sempre buscando inovar e pesquisar atividades de acordo com a necessidade de cada aluno que acompanho. (E3).

Me fez acima de tudo olhar para esses alunos com muito amor e cuidado, visto que cada um necessita de um acompanhamento diferenciado, o trabalho na realidade foge de "receitas prontas". (E4).

As participantes destacaram a relação do trabalho no subprojeto junto aos alunos PAEE e possibilitaram criar novas alternativas pedagógicas, permitindo que esses alunos fossem considerados no planejamento didático, que proporciona o acesso aos conhecimentos curriculares, para além da matrícula e convivência na escola. Para tanto, as participantes mencionam nas respostas aspectos que são coerentes com os enfrentamentos necessários à aproximação de uma prática educativa inclusiva.

Subjacentes às alternativas, emergiram os entendimentos de que não há receitas prontas para pensar o trabalho com os alunos PAEE, exige-se conhecimento, criatividade e comprometimento; o direito dos alunos a extrapolarem os limites da matrícula e da socialização, para terem acesso ao currículo escolar; e a natureza colaborativa do trabalho docente entre os professores do AEE e da sala comum.

Esses aspectos, entre outros, têm sido registrados nas várias pesquisas realizadas em todo o território nacional ou situadas em determinados contextos, ao buscarem compreender as demandas de formação dos professores que atuam com alunos PAEE, emergentes da realidade dos profissionais (MENDES; CIA; CABRAL, 2015; PLESTCH; SOUZA, 2015).

As participantes, ao serem questionadas sobre a realidade das atividades docentes voltadas aos alunos PAEE na escola, relataram dificuldades semelhantes aos contextos nos quais desenvolveram o subprojeto Pibid: 
O grande desafio é a falta de conhecimento dos profissionais, também se a família não ajudar, não estiver ali junto, torna-se mais desafiante para o professor, também entender que o aluno não é só do professor do $A E E$, o aluno é da escola. Se a gente não tiver subsídios da escola, fica difícil para o professor. (E1).

[...] O segundo desafio é em relação aos professores das salas regulares, eles não se sentem responsáveis pelos alunos, acham que esses alunos não aprendem, assim como os gestores da escola. Outro desafio é a questão da aprendizagem do aluno que não aprende simplesmente conteúdo, eles não estão ali só para aprender conteúdos, estão ali para aprender a ser cidadão realmente crítico, reflexivo e, principalmente, ter respeito. E outro desafio é que o professor do AEE não é valorizado, a desvalorização deve ser trabalhada pelo próprio professor. (E2).

O despreparo de alguns educadores para receber as crianças com NEE, ainda são muitos resistentes, sendo necessário fortalecer ainda mais as formações para esses educadores. A estrutura física das instituições que não estão preparadas para receber as crianças com NEE [...]. O currículo, pois, pela minha experiência, os currículos das escolas não são adaptadas em favor da aprendizagem dos alunos com NEE, é necessário que sejam flexíveis. A falta de parceria entre família e escola. (E3).

Um dos maiores desafios é compreender que, mesmo com necessidades educacionais especiais semelhantes, a forma de lidar com cada um é sempre diferente, precisa de todo um "jogo de cintura", materiais didáticos diferentes, forma de conduzir o ensino diferente, entre outros desafios diários. (E4).

As falas demonstram tensões e resistências presentes nas instituições onde as participantes atuavam, mobilizadas pelo trabalho com os alunos PAEE, em várias dimensões da prática escolar. Destacamos os seguintes aspectos mencionados: falta de conhecimento dos profissionais da escola, o que resultava na necessidade de formação; a dificuldade de entendimento sobre a responsabilidade de todos profissionais pela educação dos alunos PAEE, gerando a responsabilização do professor do AEE; paradoxalmente, a desvalorização do professor do AEE; ausência da compreensão de que o aluno PAEE aprende, mas exige delineamento didático e curricular específico em alguns casos e situações; melhorar a estrutura física e as condições materiais das escolas; por último, um aspecto que se constitui alicerce é compreender a matrícula do aluno na escola como direito a ser garantido pelo poder público representado pelas escolas, pois se converte em dever dos sistemas de ensino. 
Por outro lado, as falas expressam sensibilidade, capacidade de reflexão, conhecimento e resolutividade ante as atribuições e os desafios configurados na prática examinada pelas participantes. As falas demonstram, também, certa maturidade nas análises, porque as professoras conseguiram identificar os problemas e se incluírem na resolução deles, embora não tenham conseguido, no escopo das respostas formuladas, problematizarem as causas das situações evidenciadas.

\section{CONSIDERAÇÕES FINAIS}

Após a análise dos dados, constatamos que o Pibid Pedagogia contribuiu positivamente para a formação das participantes, evidenciando avanços profissionais e ganhos pessoais. Vejamos alguns aspectos implicados: ampliação dos conhecimentos, articulação entre teoria e prática; exercício constante da reflexão sobre a prática docente; aprimoramento da leitura e escrita acadêmicas, desenvolvimento da habilidade de comunicação em público; estímulo do ingresso e permanência na profissão docente. Especificamente sobre a educação especial, afora essas contribuições, as falas das participantes consistiram em criar alternativas pedagógicas para o trabalho na sala comum, no AEE e em outros espaços escolares, como possibilidade de integrar os alunos PAEE na vida relacional e na proposta curricular das instituições.

Por outro prisma, expuseram a face excludente da escola, não somente para aos alunos PAEE, posto que as evidências da pesquisa apontaram os aspectos precários da educação escolar brasileira que atuam como barreiras estruturantes à construção do paradigma inclusivo, garantido nos aportes legais.

É certo que a complementação curricular ensejada pelo Pibid acabou por denunciar as fragilidades dos cursos de licenciatura sem que isso desqualifique a trajetória da universidade para construir modelos formativos coerentes com a prática educativa a ser assumida pelos egressos. Além disso, o Pibid, na busca da integração entre a escola e a universidade, tem produzido informações e experiências relevantes que devem ancorar a criação de novas vias de inteligibilidade sobre a formação dos profissionais da educação, a partir das fragilidades, bem como de proposições inspiradas nos aspectos favoráveis identificados.

Aspectos emergentes da pesquisa, favoráveis à formação inicial, demonstram que o Pibid conseguiu, devido a sua natureza complementar, dar conta, em certa medida, de lacunas e contradições históricas constitutivas dos currículos dos 
cursos de licenciatura. A resolução desses problemas tem encontrado resistência nas disputas político-ideológicas travadas na sociedade, em função da definição do projeto histórico hegemônico, em cada época, no qual a formação humana tem papel central; portanto, repercute no perfil de professor a ser formado para subsidiar a sua concretização.

O Pibid ajuda a tensionar o campo da formação, pois consegue materializar processos formativos identificados com as demandas teórico-práticas dos bolsistas em interação com os professores experientes, mesmo submetido aos limites institucionais vigentes. Assim, as possibilidades construídas no contexto do Pibid ensejam aos futuros professores a produção de subsídios orientadores da problematização da realidade; formulação de uma compreensão dialética das dificuldades, suas causas e seus desdobramentos no espaço profissional; inscrição consciente no trabalho; e a identificação de sua tarefa nesse contexto.

\section{REFERÊNCIAS}

ASSIS, Alessandra. Pibid no contexto das políticas de formação docente. In: PENITENTE, Luciana; MENDONÇA, Sueli (Org.). Políticas para a formação de professores da educação básica: modelos em disputa. Marília: Oficina universitária; São Paulo: Cultura Acadêmica, 2016. p. 73-86.

BRASIL. Portaria n. 96, de 18 de julho de 2013. Regulamento do programa institucional de bolsa de iniciação à docência. Brasília: CAPES, 2013. Disponível em: https://www.capes.gov. br/images/stories/download/legislacao/Portaria_096_18jul13_AprovaRegulamentoPIBID. pdf. Acesso em: 18 set. 2018.

BRASIL. Política Nacional de Educação Especial na Perspectiva da Educação Inclusiva. Secretaria de Educação Especial- MEC/SEESP. Brasília: MEC, 2008. Disponível em: http:// portal.mec.gov.br/index.php?option=com_docman\&view=download\&alias=16690politica-nacional-de-educacao-especial-na-perspectiva-da-educacao-inclusiva05122014\&ltemid=30192. Acesso em: 5 maio 2018.

CENTRO DE EDUCAÇÃO, CIÊNCIAS E TECNOLOGIA DA REGIÃO DOS INHAMUNS. Formulário de submissão de subprojeto Pibid/Cecitec. Tauá: Cecitec, 2013.

DINIZ-PEREIRA, Júlio Emilio. O ovo ou a galinha: a crise da profissão docente e a aparente falta de perspectiva para a educação brasileira. Revista Brasileira de Estudos Pedagógico, . Brasília, v. 92, n. 230, p. 34-51, jan./abr. 2011. 
FARIAS, Isabel; Josete de Oliveira Castelo Branco SALES; Maria Margarete Sampaio de Carvalho Braga; Maria do Socorro Lima Marques França. Didática e docência: aprendendo a profissão. Fortaleza: Liber Livro, 2014.

FERNANDES, Cleoni Maria Barboza; CUNHA, Maria Isabel da. Formação de professores: tensão entre discursos, políticas, teorias e práticas. Inter-Ação, Goiânia, v. 38, n. 1, p. 51-65, jan./abr. 2013.

GONZATTI, S. E. M. Contribuições do Pibid para a formação inicial de professores: a terceira margem do rio. 2015. 178 f. Tese (Doutorado em Educação) - Pontifícia Universidade Católica do Rio Grande do Sul, Porto Alegre, 2015.

MENDES, Enicéia; CIA, Fabiana; CABRAL, Leonardo. Inclusão escolar e os desafios para a formação de professores em educação especial. São Carlos: Marquezine \& Manzini, 2015.

MITJÁNS MARTÍNEZ, Albertina. O direito de ser sujeito: contribuições da perspectiva histórico-cultural para a educação especial. Trabalho apresentado na mesa-redonda: educação especial e garantia de direitos. In: I Conferência Municipal de Educação, Teresina, 2005.

MOURA, Eduardo; VIANA, Cleide. Iniciação à docência: contornos e implicações de uma política de formação de professores. In: FARIAS, Isabel; JARALELINO, José; SILVESTRE, Magali (Org.). Aprender a ser professor: aportes de pesquisa sobre o Pibid. Jundiaí: Paco Editorial, 2015. p. 81-96.

OLIVEIRA, Anna. Inclusão escolar e formação de professores: o embate entre o geral e o específico. In: MENDES, Eniceia; ALMEIDA, Maria (Org.). Das margens ao centro: perspectivas para as políticas e práticas educacionais no contexto da educação especial inclusiva. Araraquara, SP: Junqueira \& Marin, 2010. p. 141-56.

OLIVERI, Andressa M. Políticas de formação de professores no Brasil: um estudo sobre o Pibid na região de Inconfidentes-MG. Ouro Preto: Editora Ufop, 2017.

PLETSCH, Márcia; SOUZA, Flávia. Observatório de educação especial e inclusão escolar: balanço das pesquisas e das práticas na Baixada Fluminense. São Carlos: Marquezine \& Manzini: ABPEE, 2015.

SANTOS, Geandra Cláudia Silva. Formação inicial complementar de professores: contribuições do Pibid para a prática com alunos da educação especial. In: ENCONTRO NACIONAL DE DIDÁTICA E PRÁTICA DE ENSINO, 19., Salvador, 2018. Anais [...]. Endipe/ UFBA, Disponível em: http://www.xixendipe.ufba.br. Acesso em: 4 out. 2018. p. 25-35. 
SOUSA, Patricia B. Formação continuada do professor do Atendimento Educacional Especializado. 2016. 50 f. Trabalho de Conclusão de Curso (Graduação em Pedagogia) Centro de Educação Ciências e Tecnologia da Região dos Inhamuns, Universidade Estadual do Ceará, Tauá, CE, 2016.

SOUZA, Maria Angélica Pires; COSTA, Maria Stela; HOLANDA, Telma Regina Pessoa. A importância do atendimento educacional especializado (AEE) para a aprendizagem dos alunos com deficiência. In: SANTOS, Gendra; RIBEIRO, Renata; SAMPAIO, Rosa; PINTO, Soraya (Org.). Inclusão: saberes, reflexões e possibilidades de uma prática em construção. Fortaleza: Eduece, 2015. p. 246-62.

UNIVERSIDADE ESTADUAL DO CEARÁ. Detalhamento da proposta institucional do Pibid/ Uece. Fortaleza: UECE, 2013.

\section{Sobre as autoras:}

Eliane Rodrigues Martins: Licenciatura plena em Pedagogia. E-mail: eliane.martins@aluno.uece.br, Orcid: http://orcid.org/0000-0003-4617-6901

Geandra Cláudia Silva Santos: Doutorado em Educação pela Universidade de Brasília (UnB), mestrado em Educação Especial pela Universidade Estadual do Ceará (Uece). Graduação em Licenciatura Plena em Pedagogia pela Universidade Regional do Cariri (Urca). Atualmente, é professora adjunta da Uece, com atuação na graduação (cursos de licenciaturas) e no Programa de Pós-Graduação em Educação (PPGE), na área de Educação Especial/Inclusiva. Coordenadora de área do Pibid da Coordenação de Aperfeiçoamento de Pessoal de Nível Superior (Capes). Líder do Grupo de Pesquisa Educação Especial na Uece, vinculado ao CNPq. Tem publicações na interface educação especial/inclusiva e subjetividade, com ênfase na formação e atuação de professores. E-mail: geandra.santos@uece.br, Orcid: http://orcid.org/0000-0002-7782-6316

\section{Recebido em: 24 de junho de 2019 Aprovado: $\mathbf{2 8}$ de julho de 2020}


